\title{
Retinoblastoma by AJCC v8 Clinical Stage
}

National Cancer Institute

\section{Source}

National Cancer Institute. Retinoblastoma by A/CC v8 Clinical Stage. NCI Thesaurus. Code C140751.

A term that refers to the clinical staging of retinoblastoma according to the American Joint Committee on Cancer, 8th edition. 